\title{
SAFE PARTIAL EMBOLIZATION OF THE SPLENIC ARTERY IN ACCORDANCE TO ITS LAST PANCREATIC BRANCH
}

\author{
By
}

\author{
Sherin W. AbdelMalek*, Abeer E. Abaskharoun* \\ and Azmy M. El-Hadidy** \\ *Department of Anatomy, Faculty of Medicine, Ain Shams University \\ ** Department of Radiology, Faculty of Medicine, Jordan University
}

\section{INTRODUCTION}

Splenectomy was a widely used procedure for treatment of some diseases like hypersplenism, thalassemia major, Hodgkin disease, ect... (Poulin et al., 1998). Moreover, it was commonly considered as a life saving technique in traumatic splenic hemorrhage and hemorrhage resulting from portal hypertension (Mishin and Ghidirim, 2004). However, nonsurgical management was favored because of morbidity related to laparotomy and splenectomy (Bader et al., 2001). Therefore, Han et al. (1997), Sockrider et al. (2001) and Wahl et al. (2004) thought that splenic artery embolization could be performed preoperatively or as an alternative to surgery to obtain partial or total organ ablation. However, Inagawa et al. (2004) pointed out that in every embolization procedure, inadvertent passage of embolic material to the vessels of non-target organs was the most dangerous complication. In splenic artery embolization, this complication may occur in one or more of the pancreatic branches of the splenic artery causing pancreatitis (Rose et al., 1998). The left part and the tail of the pancreas are specifically concerned with this complication as the splenic artery is the only source of its arterial supply (Pandey et al., 2004). Although the embolic material may involve the gastric branches of the splenic artery, yet the extensive anastomosis and collateralization between short gastric and left gastroepiploic arteries with the rest of gastric arterial supply assure sufficient blood supply to the stomach (Vandamme and Bonte, 1988) Consequently, Harned et al. (1998) and Kimura et al. (2003) preferred the selective or partial splenic embolization where one or two branches of the splenic artery were involved, especially where a false aneurysm or frank extravasation could be shown to arise from a discrete source. This could be explained by Palsson et al. (2003) who assumed that partial embolization reduced the incidence of complications following splenic artery embolization, which included splenic infarction, rupture, abscess, sepsis and inadvertent non-target embolization. This latter complication was particularly recorded in the pancreas with high incidence of pancreatitis. Obviously, to avoid this potentially life-threatening complication, an attempt knowledge of the vascular anatomy of the splenic artery and its branches is required. Of particular importance is the exact anatomical ori- 
gin of the last pancreatic branch from the splenic artery, since the tip of the microcatheter should be distal to this origin to achieve a safe embolization to the splenic artery.

Therefore, it became the aim of the present study to measure the distance between the last pancreatic branch and the splenic hilum in cadavers as well as on angiograms performed to living subjects in order to define a safe region through which partial splenic embolization can be performed.

\section{MATERIALS AND METHODS}

Twenty-two dissecting room cadaveric specimens and twenty-nine splenic angiographies were studied. The cadavers included were fourteen males and eight females. Their abdomens were opened and the lesser omentum was removed. The coeliac trunk with its branches were identified and dissected. Then the vessels in the gastrosplenic ligament to the hilum of the spleen were identified and followed and the left gastroepiploic artery was followed through the greater curvature of stomach. The stomach was reflected upward by cutting through the line of attachment of the greater omentum to the pancreas. Consequently, the anterior surface of the pancreas was exposed and its limits were defined. Next, the tail of pancreas was lifted away from spleen and its body was eased from the posterior abdominal wall. Then, the tail and body of pancreas were turned to the right stripping the splenic artery with its branches passing to the gland which were carefully identified and dissected. All other surrounding vessels, together with the bile duct, were defined and divided. Finally, the pancreas, the splenic artery with all its pancreatic branches, the stomach and the spleen were removed in one piece. The distance between the last pancreatic branch of the splenic artery and the hilum of the spleen was measured.

For radiological evaluation, selective splenic arteriography of twentytwo patients (thirteen males and sixteen females aging from 34-67 years) was done in Jordanian University Hospital. These patients were referred to the radiology department requesting femoral artery catheterization and aortic angiography for variable indications (nine females were with lower gastrointestinal bleeding, seven females and two males were hypertensive suspecting renal artery stenosis and eleven males with peripheral arterial diseases). During the processing of each catheterization, the splenic artery was selectively catheterized. All patients signed informed consent. An amount of $10-20 \mathrm{ml}$ of Ultravest contrast media $(370 \mathrm{mg} / \mathrm{ml})$ was injected in the proximal part of the splenic artery. Video recording and image analysis were done using Philips inturis suite lite computer soft ware. In all angiographies, the straight distance between the origin of the last pancreatic branch of the splenic artery and the splenic hilum was recorded and compared with the cadaveric measurements. 


\section{RESULTS}

In the anatomical measurements of the cadaveric specimens, the average of the straight distance between the origin of the last pancreatic branch and the splenic hilum was $31.8 \mathrm{~mm} \pm 5.3$ (table 1; figs. 1,2). On selective angiograms' measurements, the average of the straight distance between the origin of the last pancreatic branch and the splenic hilum was $32.4 \mathrm{~mm} \pm 5.5$ (table 2; figs. $3,4,5$ ). The shortest distance recorded was $21 \mathrm{~mm}$ and $19 \mathrm{~mm}$ in cadaveric specimens and angiograms respectively. In all cadaveric specimens, the splenic artery appeared to be slightly tortuous (figs. 1, 2). However, marked variation of the splenic artery tortuosity was noticed in the angiograms. Highly tortuous splenic artery was noticed in 14 angiograms belonging to six males and eight females (fig. 3). Minimal tortuosity was apparent in nine angiograms belonging to five males and four females (fig. 5). On the other hand, six angiograms done for two males and four females showed straight splenic artery (fig. 4). In three cadaveric specimens, the left gastroepiploic artery originated from the splenic artery before the last pancreatic branch (fig. 1) and in the rest of the cadavers, it originated near the splenic hilum (fig. 2). On the other hand, out of the twenty-nine patients to whom the angiogram was performed, four cases showed the left gastroepiploic artery originated proximal to the last pancreatic branch of the splenic artery (fig. 4).

\section{DISCUSSION}

Partial splenic artery embolization has been highly evaluated and recommended since the 1990s as the treatment of choice for hypersplenism, splenomegaly and hemorrhagic events (Shimizu et al., 2003; Ozdogo et al., 2004; Sekikawa et al., 2004). However, Sakai (2002), Inagawa et al. (2004) and Moreno (2004) found that the most hazardous complication of this procedure was inadvertent passage of embolic material to the pancreatic branches of the splenic artery causing pancreatitis. Therefore, in the present work, the distance between the last pancreatic branch of the splenic artery and the splenic hilum was measured trying to define a safe region in which partial splenic embolization can be performed. In the current work, the average of this distance was $31.8 \mathrm{~mm}$ in twenty-two cadavers and $32.4 \mathrm{~mm}$ on twenty-nine angiograms. The results of the present study demonstrated clearly that this distance was variable a point not recognized in several current anatomy books. The shortest distance found in this study was $21 \mathrm{~mm}$ in cadavers and $19 \mathrm{~mm}$ on angiograms. Consequently, to avoid pancreatitis, the present study recommended embolization to be done in the distal $19 \mathrm{~mm}$ of the splenic artery. Previously, in order to avoid pancreatitis, Rose et al. (1998) performed temporary splenic artery balloon occlusion for protection of nonsplenic vascular beds, like pancreatic branches, during splenic embolization. Despite meticulous attention 
Table 1: Table showing the sex of the cadavers and the straight distance (D) between the last pancreatic branch of the splenic artery and the splenic hilum.

\begin{tabular}{|c|c|c|}
\hline Serial number & Sex & $D[\mathrm{~mm}]$ \\
\hline 1 & Male & 41 \\
\hline 2 & Male & 26 \\
\hline 3 & Male & 32 \\
\hline 4 & Male & 29 \\
\hline 5 & Male & 30 \\
\hline 6 & Male & 31 \\
\hline 7 & Male & 29 \\
\hline 8 & Male & 28 \\
\hline 9 & Male & 27 \\
\hline 10 & Male & 33 \\
\hline 11 & Male & 37 \\
\hline 12 & Male & 34 \\
\hline 13 & Male & 32 \\
\hline 14 & Male & 36 \\
\hline 15 & Female & 40 \\
\hline 16 & Female & 21 \\
\hline 17 & Female & 24 \\
\hline 18 & Female & 26 \\
\hline 19 & Female & 35 \\
\hline 20 & Female & 32 \\
\hline 21 & Female & 38 \\
\hline 22 & Female & 38 \\
\hline \multicolumn{2}{|c|}{ Mean } & 31.8 \\
\hline \multicolumn{2}{|c|}{ Standard deviation } & 5.3 \\
\hline
\end{tabular}


Table 2: Table showing the sex, age and the straight distance (D) between the last pancreatic branch of the splenic artery and the splenic hilum as seen in angiograms.

\begin{tabular}{|c|c|c|c|}
\hline $\begin{array}{c}\text { Serial } \\
\text { number }\end{array}$ & Sex & Age & $D[\mathrm{~mm}]$ \\
\hline 1 & Male & 38 & 42 \\
\hline 2 & Male & 40 & 34 \\
\hline 3 & Male & 45 & 32 \\
\hline 4 & Male & 48 & 19 \\
\hline 5 & Male & 53 & 29 \\
\hline 6 & Male & 55 & 30 \\
\hline 7 & Male & 55 & 28 \\
\hline 8 & Male & 57 & 37 \\
\hline 9 & Male & 59 & 29 \\
\hline 10 & Male & 61 & 30 \\
\hline 11 & Male & 61 & 37 \\
\hline 12 & Male & 63 & 27 \\
\hline 13 & Male & 67 & 41 \\
\hline 14 & Female & 34 & 28 \\
\hline 15 & Female & 37 & 34 \\
\hline 16 & Female & 40 & 29 \\
\hline 17 & Female & 41 & 36 \\
\hline 18 & Female & 44 & 29 \\
\hline 19 & Female & 47 & 31 \\
\hline 20 & Female & 51 & 37 \\
\hline 21 & Female & 51 & 27 \\
\hline 22 & Female & 54 & 39 \\
\hline 23 & Female & 55 & 40 \\
\hline 24 & Female & 57 & 32 \\
\hline 25 & Female & 59 & 25 \\
\hline 26 & Female & 59 & 26 \\
\hline 27 & Female & 61 & 35 \\
\hline 28 & Female & 62 & 38 \\
\hline 29 & Female & 65 & 39 \\
\hline \multicolumn{3}{|c|}{ Mean } & 32.4 \\
\hline \multicolumn{3}{|c|}{ Standard deviation } & 5.5 \\
\hline
\end{tabular}




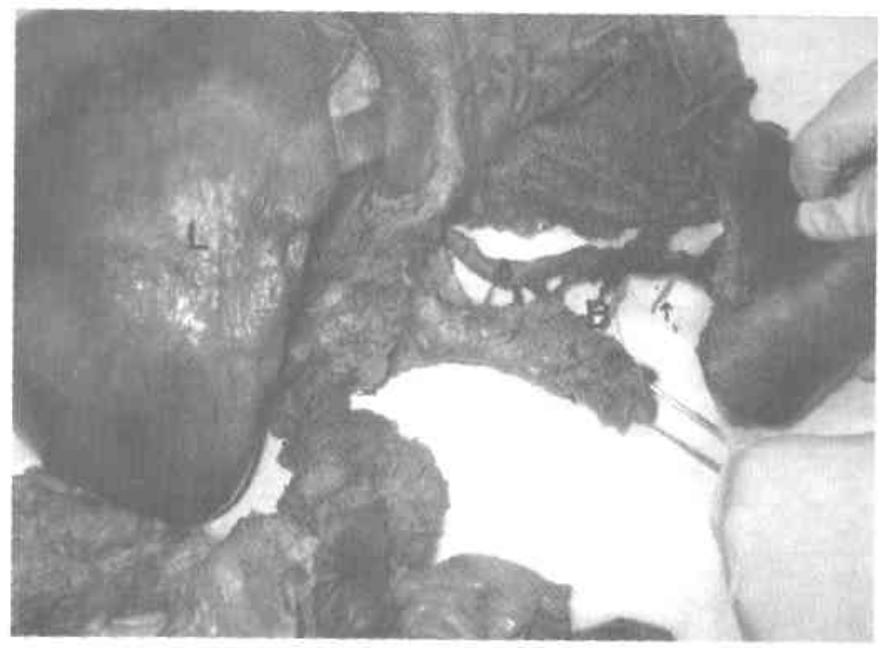

Fig. (1): Photograph of a specimen belonging to a male cadaver showing the pancreatic branches $(B)$ of the splenic artery $(A)$. Note the last pancreatic branch of the splenic artery $(\uparrow)$ and the hilum $(\mathrm{H})$ of the spleen. The left gastroepiploic artery $(G)$ arises from the splenic artery before the last pancreatic branch $(\uparrow)$. The liver $(L)$ is overlapped by the reflected stomach $(T)$.

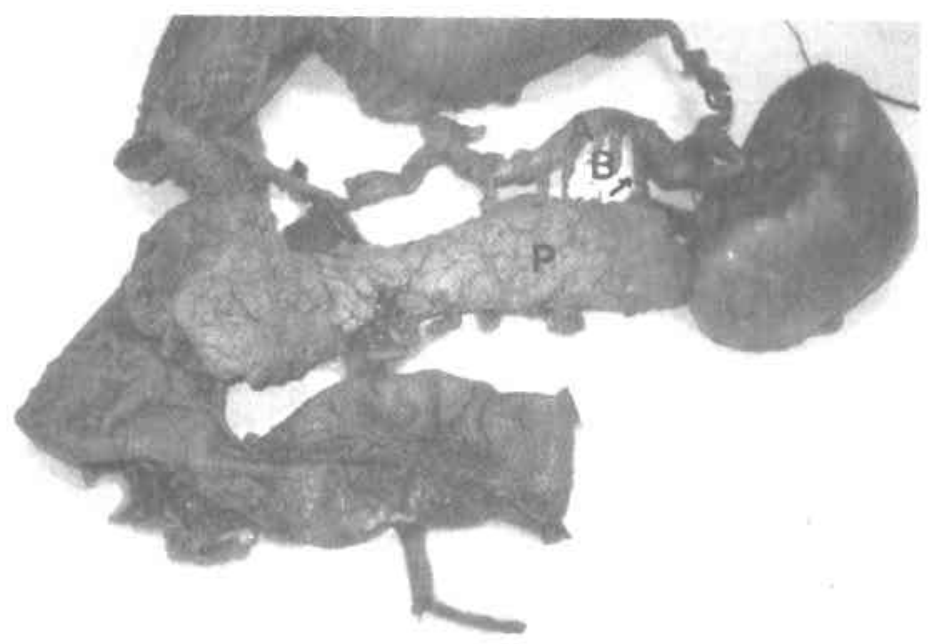

Fig. (2): Photograph of a specimen taken from a female cadaver showing slightly tortuous splenic artery $(A)$ running superior to the pancreas $(P)$. The pancreatic branches $(B)$ of the splenic artery are apparent. Note the last pancreatic branch of the splenic artery $(\uparrow)$ and the hilum $(H)$ of the spleen. The left gastroepiploic artery (G) arises from the splenic artery near the hilum. 

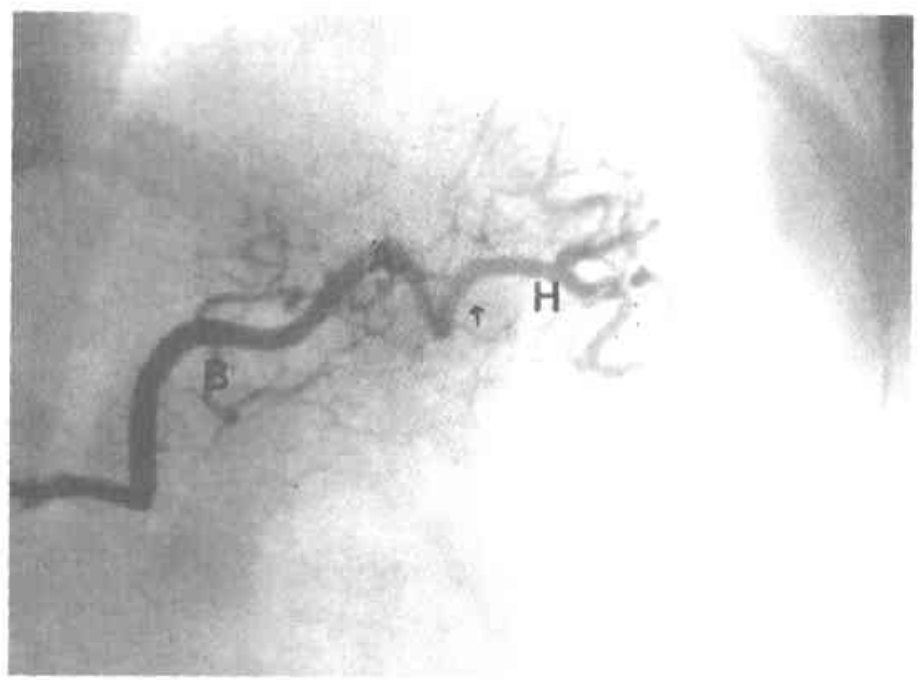

Fig. (3): Angiogram belonging to a 45-years-old male showing the tortuous splenic artery $(A)$ with its pancreatic branches $(B)$. The shadow of the hilum $(H)$ of the spleen is apparent where the splenic artery starts to divide into its segmental branches. Note the last pancreatic branch of the splenic artery $(\uparrow)$.

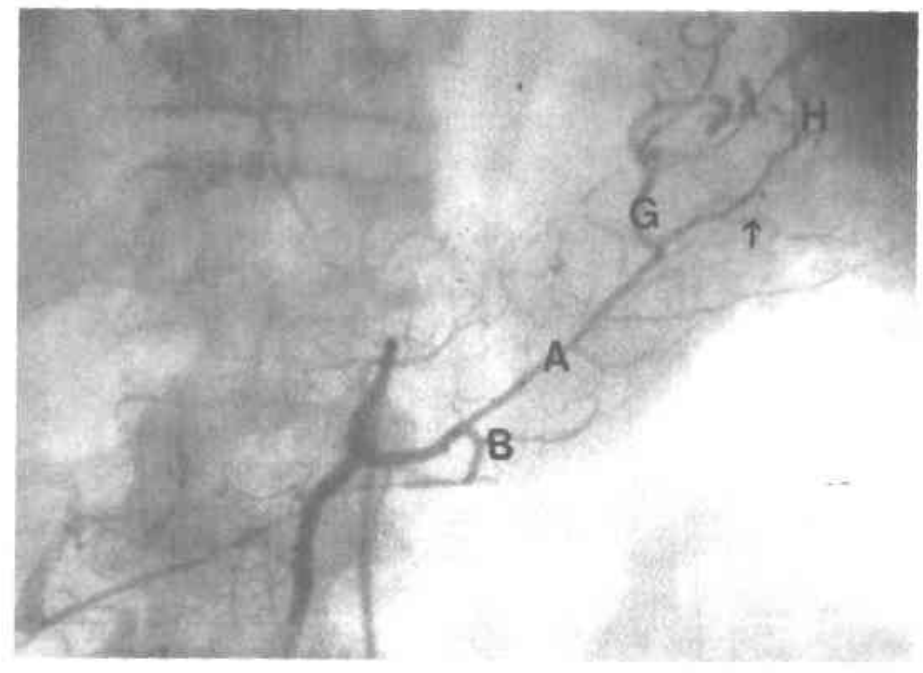

Fig. (4): Angiogram belonging to a 53-years-old female showing straight splenic artery (A) with its pancreatic branches (B). Note the last pancreatic branch of the splenic artery $(\uparrow)$ and the splenic hilum $(H)$. The left gastroepiploic artery $(G)$ arises from the splenic artery before the last pancreatic branch ( $\uparrow$. 


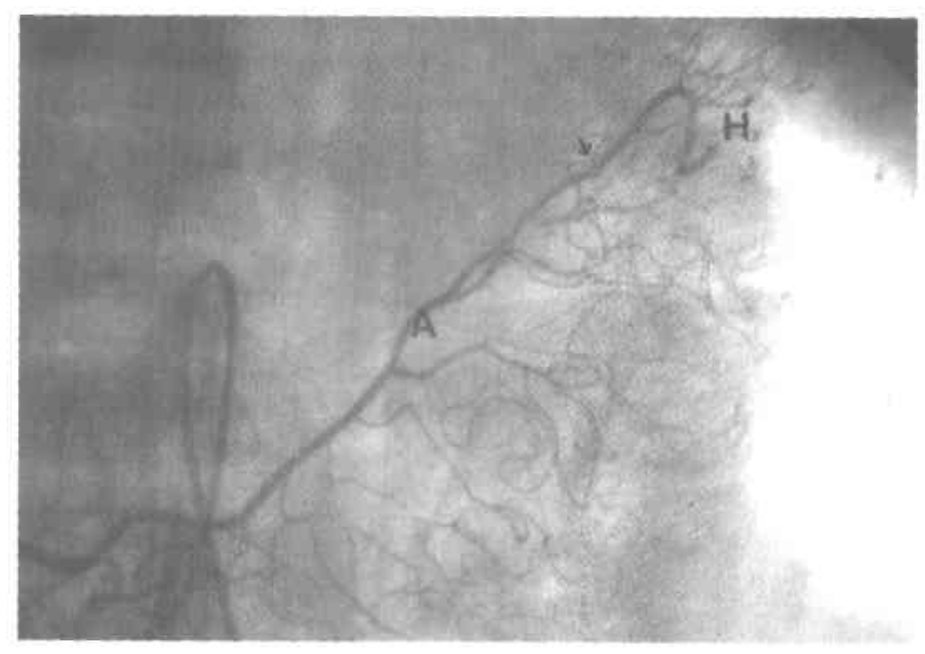

Fig. (5): Angiogram belonging to a 40-years-old female showing minimal tortuosity of the splenic artery (A). Note the last pancreatic branch of the splenic artery $(\uparrow)$ and the splenic hilum $(H)$.

of the authors, three cases out of fifteen patients in their studies developed pancreatitis following the procedure. Later on, Sindel et al. (2001) were the only authors to the best of our knowledge to describe the average distance between the last pancreatic branch of the splenic artery and the splenic hilum. These authors recommended that to avoid the risk of pancreatitis, the embolic material should be delivered in the distal $30.7 \mathrm{~mm}$ of the splenic artery which was the smallest distance between the origin of the last pancreatic branch and the splenic hilum the authors found on splenic angiograms. Unfortunately, one out of twelve of their patients developed pancreatitis in spite of taking into consideration their previously recommended measurements. This could be explained through comparing the measurements recorded by the current study and those of Sindel et al. (2001). A difference of $11.7 \mathrm{~mm}$ between the minimum recorded distance of Sindel et al. (2001) $(30.7 \mathrm{~mm})$ and that of the present study $(19 \mathrm{~mm})$, might explain the occurrence of pancreatitis in the study of the former authors who obviously did not exclude all the pancreatic branches. Therefore, it could be assumed that the safe distance through which the embolic material should be injected in the splenic artery to avoid pancreatitis was more accurately reported by the present study through performing measurements on a wider scale exceeding double the samples of sindel et al. (2001) who studied only ten cadavers and twelve angiograms.

The average of the cadaveric measurements in the current study was lower than that of the arteriographic measurements. This could be explained by slight tissue shrinkage produced by formalin fixation in cadavers (Larsen et al., 2003). 
Vandamme and Bonte (1986) described the splenic artery to be composed of four anatomical divisions, including suprapancreatic, pancreatic, prepancreatic and prehilar segments. Moreover, Waizer et al. (1989) reported the lengths of these splenic arterial segments to be 2.5, 10.5, 2.5 and $1.5 \mathrm{~cm}$ respectively. Accordingly, as the present study found the last pancreatic branch to arise $31.8 \pm 5.3 \mathrm{~mm}$ from the splenic hilum in cadavers and $32.4 \pm 5.5 \mathrm{~mm}$ on angiograms, it could be assumed that the last pancreatic branch originated from the prepancreatic segment of the splenic artery.

In addition, this work found variations in the splenic artery tortuosity specially, on angiograms, although in cadavers the splenic artery was nearly tortuous in all the specimens. On the contrary, Borley et al. (1995) described marked variation in tortuosity of this artery in both cadavers and angiograms with no correlation to sex difference. Sylvester et al. (1995) suggested increasing tortuosity of the splenic artery with age. This could explain the tortuosity found in all cadaveric specimens in the present study as they usually represented an elderly group. On the other hand, variability in the tortuosity recorded on angiograms could be referred to the variation of the age of the patients included in this study.

The left gastroepiploic artery was known to arise from the distal portion of the splenic artery near the splenic hilum (Vandamme and Bonte, 1986). This was also recorded in the majority of the samples included in the current work. However, in a minority of cases (three cadavers and four angiograms) in the present study, the left gastroepiploic artery was seen to arise from the splenic artery proximal to the last pancreatic branch. This could explain the occurrence of pancreatitis in patients to whom identification of the safe site to perform partial splenic embolization depended on the location of the left gastroepiploic artery being distal to the last pancreatic branch near the hilum (Sakai et al., 2002). Unfortunately, missing the cases where this artery originated proximal to the last pancreatic branch involved embolization of this branch and pancreatitis. Consequently safety of the procedure should depend on the exact anatomical location of the last pancreatic branch rather than the left gastroepiploic artery.

In conclusion, this study might assume that in order to achieve a safe splenic embolization and avoid the risk of pancreatitis, embolic materials should be delivered through a catheter whose tip is located in the distal 19 $\mathrm{mm}$ of the splenic artery.

\section{SUMMARY}

Recently, partial splenic artery embolization has been highly evaluated as an alternative to splenectomy to obtain organ ablation. Pancreatitis was recorded to be the most dangerous complication of this procedure. 
This could be referred to the inadvertent passage of the embolic material through the pancreatic branches of the splenic artery. Therefore, the purpose of the present study was to provide an accurate measurement of the distance between the last pancreatic branch of the splenic artery and the splenic hilum through which a safe embolization could be performed. In the present work, this distance was measured in 22 cadavers of both sexes to whom careful dissection of the splenic artery and its pancreatic branches was done. In addition, this distance was also recorded in selective splenic arteriography done for 29 living subjects of both sexes. The mean and standard deviation were calculated and compared between cadaveric specimens and angiograms. The smallest distance recorded was $19 \mathrm{~mm}$. It could be concluded that in order to achieve a safe splenic artery embolization and avoid the risk of pancreatitis, embolic material should be delivered through a catheter whose tip is located in the distal $19 \mathrm{~mm}$ of the splenic artery.

\section{REFERENCES}

1. Bader-Meunier, B.; Husseini, K.; Nouyrigat, V. and Pariente, D. (2001): Partial splenic embolization in lymphangiomatosis. J. Pediatrics, 138: 613-614.

2. Borley, N. R.; Mcfarlane, J. M. and Ellis, H. (1995): A comparative study of the tortuosity of the splenic artery. Clin. Anat., 8: 219-221.

3. Han, M.J.; Zhao, H.G.; Ren, K.; Zhao, D.C.; Xu, K. and Zhang, X. T. (1997): Partial splenic embolization for hypersplenism concomitant with or after arterial embolization of hepatocellular carcinoma in 30 patients. Cardiovasc. Intervent Radiol, 20: 125-127.

4. Harned, R. K.; Thompson, H. R.; Kumpe, D. A.; Narkiwicz, M. R. and Sokol, R. J. (1998): Partial splenic embolization in five children with hypersplenism: effects of reduced-volume embolization on efficacy and morbidity. Radiol., 209: 803-806.

5. Inagawa, S.; Takehara, Y; Nasu, H. and Isogai, S. (2004): Interventional radiology in the splanchnic arteries. Nippon Geka Gakkai Zasshi., 105(6): 359-363.

6. Kimura, F.; Ito, H.; Shimizu, H.; Togawa, A.; Otsuka, M.; Yoshidome, H.; Shimamura, F.; Kato, A.; Nukui, Y.; Ambiru, S. and Miyazaki, M. (2003): Partial splenic embolization for the treatment of hereditary spherocytosis. Am. J. Roentgenol., 181(4): 1021- 1024.

7. Larsen, M.; Bjarkam, C. R.; Stoltenberg, M.; Sorensen, J. C. and Danscher, G. (2003): An autometallographic technique for myelin staining in formaldehyde-fixed tissue. Histol. Histopathol., 18(4): 1125-1130. 
8. Mishin, I. and Ghidirim, G. (2004): Accessory splenectomy with gastroesophageal devascularization for recurrent hypersplenism and refractory bleeding varices in a patient with liver cirrhosis: report of a case. Surg Today., 34(12): 1044-1048.

9. Moreno, A.; Barcena, R.; Blazquez, J.; Quereda, C.; Gil-Grande, L.; Sanchez, J.; Moreno, L.; Perez-Elias, M.J.; Antela, A.; Moreno, J.; delCampo, S. and Moreno, S. (2004): Partial splenic embolization for the treatment of hypersplenism in cirrhotic HIV/HCV patients prior to pegylated interferon and ribavirin. Antivir. Ther., 9(6): 1027-1030.

10. Ozdogu, H.; Boga, C.; Oguzkurt, L. and Kizilkilic, E. (2004): Partial splenic embolization in myelodysplastic syndrome associated with immune thrombocytopenia. J. Thrombol., 18 (3): 213-216

11. Palsson, B.; Hallen, M.; Forsberg, A.M. and Alwmark, A. (2003): Partial splenic embolization: long-term outcome. Langenbecks Arch Surg., 387 (11-12): $421-6$.

12. Pandey, S. K.; Bhattacharya, S.; Mishra, R. N. and Shukla, V.K. (2004): Anatomical variations of the splenic artery and its clinical implications. Clin Anat., 17(6): 497-502.

13. Poulin, E. C.; Mamazza, J. and Schlachta, C. M. (1998): Splenic artery embolization before laparoscopic splenectomy. Surg. Endosc., 12: $870-875$.

14. Rose, S. C.; Lim, G. M.; Arellano, R. S.; Easter, D. B. and Roberts, A. C. (1998): Temporary splenic artery balloon occlusion for protection of nonsplenic vascular beds during splenic embolization. AJR Am. J. Roentgenol., 170: 1186-1188.

15. Sakai, T.; Shiraki, K.; Inoue, H.; Sugimoto, K.; Ohmori, S.; Murata, K.; Takase, K. and Nakano, T. (2002): Complications of partial splenic embolization in cirrhotic patients. Dig Dis Sci., 47(2): 388-391.

16. Sekikawa, Z.; Takebayashi, S.; Kurihara, H.; Lee, J.; Niwa, T.; Kawamoto, M.; Yamamoto, T.; Suzuki, J.; Sugiyama, M. and Inoue, T. (2004): Factors affecting clinical outcome of patients who undergo transcatheter arterial embolization in splenic injury. Br J Radiol., 77: 308-311.

17. Shimizu, T.; Tajiri, T.; Yoshida, H.; Yokomuro, S.; Mamada, Y.; Taniai, N.; Kawano, Y.; Takahashi, T.; Arima, Y.; Aramaki, T. and Kumazaki, T. (2003): Hand-assisted laparoscopic hepatectomy after partial splenic embolization. Surg. Endosc., 17(10): 1676. 
18. Sindel, M.; Sarikcioglu, L.; Ceken, K. and Yilmaz, S. (2001): The importance of the anatomy of the splenic artery and its branches in splenic artery embolization. Folia Morphol., 60 (4): 333-336.

19. Sockrider, C.S.; Boykin, K.N.; Green, J.; Marsala, A.; Mladenka, M. and Zibari, G.B. (2001): Partial splenic embolization for hypersplenism after liver transplantation. Transplant. Proc., 33(7-8): 3472-3473

20. Sylvester, P. A.; Stewart, R. and Ellis, H. (1995): Tortuosity of the human splenic artery. Clin. Anat., 8: 214-218.

21. Vandamme, J.P. and Bonte, J. (1986): Systematization of the arteries in the splenic hilus. Acta Anat. (Basel), 125(4): 217-224.

22. Vandamme, J.P. and Bonte, J. (1988): The blood supply of the stomach. Acta Anat. (Basel), 131(2): 89-96.

23. Wahl, W.L.; Ahrns, K.S.; Chen, S.; Hemmila, M.R.; Rowe, S. A. and Arbabi S. (2004): Blunt splenic injury: operation versus angiographic embolization. Surgery, 136(4): 891-899.

24. Waizer, A.; Beniel, J.; Ziv, Y. and Dintesman, M. (1989): Clinical implications of anatomic variations of the splenic artery. Surg. Gynecol. Obstet., 168: $57-58$. 


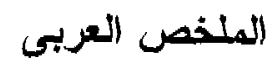

الإنسداد الجزئه الآمن لشريان الطحال في ضوي آخر فرع منه للبنكرياس

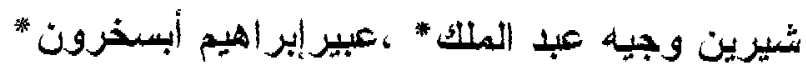

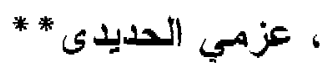

*قسم التنسريح ، كلية الطب ، جامعة غين شهس

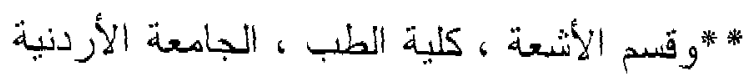

بتم استخدام الانسداد الجزئي لشريان الطحال في هذه الآونه كثيرا لعمليات

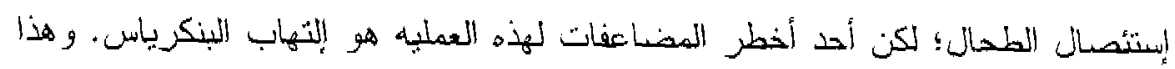

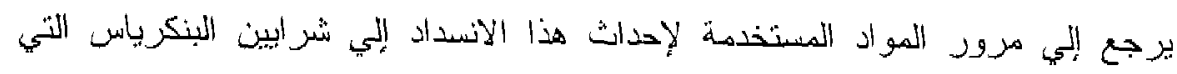

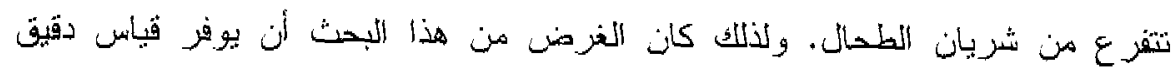

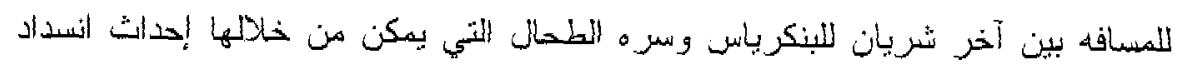

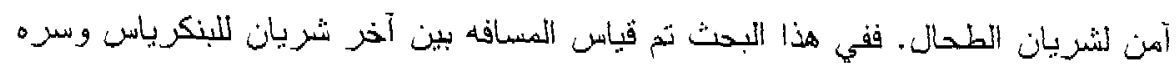

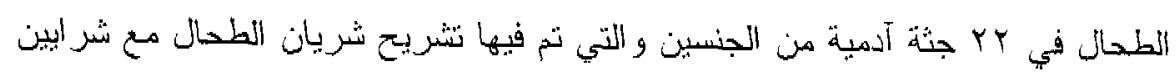

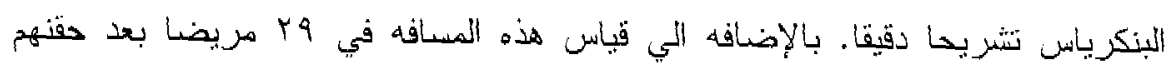

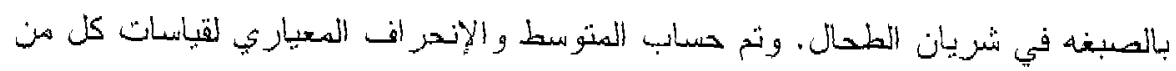

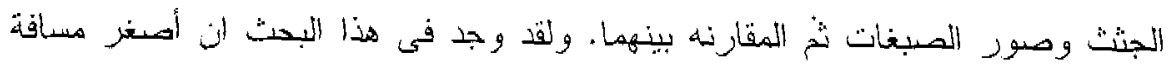
هي 19 هم. و هكذا استتنت هذه الدرسية إنه لتحفيق أنسداد جزئي لشريان الطحال

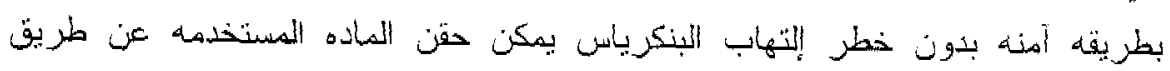
قسطر هُرفها متو اجد في آخر 19 مم من شريان الطحال قبل سره الطحال.

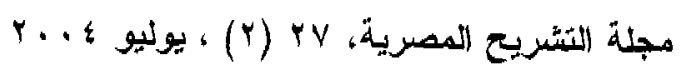

